\title{
PSICOLOGIA E DESIGUALDADE SOCIAL: UMA REFLEXÃO SOBRE LIBERDADE E TRANSFORMAÇÃO SOCIAL
}

\author{
Bader Burihan Sawaia \\ Pontifícia Universidade Católica de São Paulo, São Paulo, Brasil
}

\begin{abstract}
RESUMO: Por trás da desigualdade social há sofrimento, medo, humilhação, mas há também o extraordinário milagre humano da vontade de ser feliz e de recomeçar onde qualquer esperança parece morta. A Psicologia tem o dever de resguardar essa dimensão humana nas análises e intervenções sociais, desmentindo as clássicas imagens dos desvalidos contentando-se em se conservarem vivos. Assim, ela colabora com o aperfeiçoamento de políticas sociais, evitando mecanismos de inclusão social perversa. A concepção de afeto de Espinosa e a de liberdade de Vigotski são pressupostos importantes: um afeto que é a base da ética e da política; uma liberdade que exige a ação coletiva e não se confunde com livre-arbítrio, tendo por base a criatividade e a imaginação. Nessa perspectiva, um dos desafios do combate à desigualdade social é elucidar o sistema afetivo/criativo que sustenta a servidão nos planos (inter)subjetivo e macropolítico, para planejar uma práxis ético/estética de transformação social.
\end{abstract}

PALAVRAS-CHAVE: afeto; liberdade; políticas públicas; transformação social; sentido; potência de ação; inclusão perversa.

\section{PSYCHOLOGY AND SOCIAL INEQUALITY: A REFLECTION ON FREEDOM AND SOCIAL TRANSFORMATION}

\begin{abstract}
Behind social inequality there is suffering, fear, humiliation, but there is also the extraordinary human miracle will to be happy and to start where any hope seems to be dead. Psychology has a duty to protect this human dimension in the analysis and social interventions, belying the classic images of the destitute ones being merely grateful for being alive. Thus, it collaborates with the development of social policies avoiding mechanisms of perverse social inclusion. The design of affection for Spinoza and of freedom for Vygotsky are major preconditions: an affection is the basis of ethics and politics, freedom requires collective action and it is not to be confused with freewill, based on creativity and imagination. From this perspective, one of the challenges of combating social inequality is to elucidate the affective / creative system which holds the servitude in the (inter) subjective and macro-political plans, to plan an ethical / aesthetic practice of social transformation.
\end{abstract}

KEYWORDS: affection; freedom; public policy; social change; direction; power of action; perverse inclusion.

O tema deste artigo destaca uma relação inquestionável entre subjetividade, desigualdade e transformação social. Nenhum referencial teórico das Ciências Humanas a refuta. Grandes pensadores se debruçaram sobre ela, criando categorias analíticas indispensáveis à sua análise, dentre as quais se destacam os poderosos conceitos marxistas de alienação e ideologia. Freud também a considerou na avaliação do alcance da terapia psicanalítica. Defendia o direito dos pobres de terem acesso à psicanálise, mas temia que eles fossem resistentes à terapia por estarem menos "dispostos a renunciar às suas neuroses", porque não viam atrativos para voltar às suas pobres vidas atravessadas por sofrimento e dificuldades de sobrevivência (Freud, 1968).

A polêmica ocorre em torno do como se dá essa relação: se a subjetividade determina a desigualdade ou, ao contrário, se a desigualdade determina a subjetividade.
Um exemplo da primeira concepção é a hipótese, que permitiu a emergência da ciência econômica, de que os homens se comportam sempre de maneira egoisticamente racional na perseguição da maximização de seus próprios interesses, o que significa afirmar que a afetividade é a base da organização social (Bodei, 1995, p. 18).

Como exemplo da segunda concepção, tem-se a pesquisa sobre o suicídio realizada pelo pai da Sociologia, Durkheim, que, fazendo uma crítica à recém-criada ciência psicológica, procura demonstrar que o fato individual não tem força social. Para ele, até mesmo o suicídio, que aparentemente é um ato que depende da vontade de cada um, na verdade é um fato social, determinado por variáveis objetivas e não subjetivas (Durkheim, 2003). É preciso lembrar que o paradigma científico clássico não aceita a subjetividade como obje- 
to de estudo, por seu caráter instável, imprevisível, sem fisicidade, portanto, não observável e mensurável.

Por trás desse acirrado debate, há, todavia, um consenso. Independentemente da direção causal que se defende, a avaliação é a de que a relação é pela negatividade. A subjetividade - quer seja determinante, quer seja determinada - é sempre a vilã, a que explica a desigualdade e obstaculiza qualquer ação transformadora. Dessa forma, a única maneira de tratá-las só pode ser por controle, disciplinarização ou eliminação, e até mesmo pela patologização.

Todos temos o firme propósito de assegurar a presença da Psicologia Social na análise das questões sociais como um saber militante em nossas atuações em comunidade, em movimentos sociais, em políticas públicas de saúde e de assistência social, bem com em outras ações de caráter coletivo, e enfrentamos dificuldades geradas pela falta de referencial analítico que oriente as práticas emancipadoras. O psicólogo, muitas vezes por medo do psicologismo e da redução do indivíduo a si mesmo, isolado do social, tende a abandonar o sujeito, suas alegrias e seus sofrimentos, tudo o que representa o singular, e voltar-se exclusivamente à análise e à atuação nas determinações sociais. Cria, assim, uma cilada mortífera à sua práxis: se o sujeito é um objeto que não pode se defender das determinações sociais, não há lugar para a ideia de transformação da sociedade; ou, uma vez que a subjetividade é efeito mecânico da presença do capitalismo e a individuação é exclusivamente a subjetivação de processos sóciohistóricos de submissão, resta-nos apenas conhecer e criticar os mecanismos de adestramento. Há também os que consideram que as políticas públicas, por seu caráter abrangente, se fazem antagônica à subjetividade e à singularidade. Em meio a esse debate, a Psicologia está, cada vez mais, sendo chamada - corretamente, em minha opinião - a participar das políticas públicas de superação da desigualdade social, e não só na área da saúde, mas na da assistência social.

É importante ressaltar que esse debate não se resume à briga entre áreas do saber. Ele é epistemológico. Por trás dele, está a falsa dicotomia entre objetividade e subjetividade, e ainda entre a concepção de homem a reboque da sociedade ou à frente dela, que atravessa a história das ideias e, portanto, da Psicologia. Trata-se de uma dicotomia que, atualmente, estamos todos na busca necessária de sua superação.

Pretendo apresentar, neste texto, um dos caminhos trilhados nessa busca, configurado de dentro da Psicologia sócio-histórica, que analisa a relação entre subjetividade e desigualdade procurando romper a dualidade social/singular. É uma perspectiva analítica que entende que por trás da desigualdade social há vida, há sofrimento, medo, humilhação, mas também há o mais extraordinário milagre humano: a vontade de ser feliz e de recomeçar ali onde qualquer esperança parece morta. Há, portanto, o homem por inteiro, de corpo e mente, emoção e razão, determinado e determinante da sociedade, de forma que o que acontece com um afeta o outro. Nessa concepção, a subjetividade deixa de ser perturbadora para ser constituinte da objetividade social.

Estou falando da perspectiva da Psicologia Social construída na PUC-SP por Silvia Lane. Tive o privilégio de ser sua orientanda de mestrado e doutorado. Sou uma socióloga que, no início dos anos 70, como vários outros, buscava subsídios na Psicologia para trabalhar a ideia de sujeito dentro da teoria marxista sem reduzilo a categorias sociais, de modo que pudesse falar de emoção, subjetividade e desejo na análise de questões sociais sem que isso significasse reduzir tais questões ao voluntarismo ou cair em psicologismo. Encontrei o que procurava na produção e nas aulas de Lane, que, à época, percorria o caminho inverso.

Silvia Lane buscava no marxismo a possibilidade analítica de inserir o homem e as categorias do psiquismo humano na história e na sociedade de classes, um homem em movimento. Pude compartilhar seu entusiasmo, ao retornar de um Congresso da Sociedad Interamericana de Psicología1, com a conferência de Baró, que, segundo ela, instigou a todos perguntando por que a psicologia latino-americana não conseguia entender e elaborar propostas de ação para superar a alienação de seus povos.

Em 1979, a SIP, em seu XVII Congresso Internacional, aprova a criação de associações nacionais visando à produção de um saber psicossocial militante voltado às problemáticas de cada país. Silvia aceita o desafio, criando a Associação Brasileira de Psicologia Social ABRAPSO, bem como reformulando o Programa de Pós-Graduação em Psicologia Social da PUC-SP, para engajá-lo mais explicitamente nos problemas sociais brasileiros. Desde então, ela não parou mais de pesquisar e de buscar parcerias na Psicologia, na Sociologia e na Linguística, visando especialmente à criação de uma teoria capaz de ligar a Psicologia, ontológica e epistemologicamente, à ação política transformadora.

Um pensador que colaborou muito com a obra de Lane e que tem muito a dizer sobre a ação política da Psicologia é Vigotski. Esse grande teórico (1896-1934) é um crítico de arte e advogado que, insatisfeito com as teorias formalistas e sociológicas, buscou a Psicologia para compreender a criatividade artística e sua permanência na história da humanidade, apesar das poderosas determinações sociais bloqueadoras. Encontra uma Psicologia em crise, que não the fornece respostas, afogada em falsos confrontos entre teorias que reduzem a questão psicológica a apenas uma das dimensões que a constitui - o inconsciente, a consciência, o compor- 
tamento ou a cognição -, como se o homem de cada uma dessas teorias fosse diferente daquele estudado pelas demais. Inconformado, vai buscar na dialética de Marx2 e na filosofia monista de Espinosa3 orientação para esses antagonismos retalhadores do homem.

Apresentar a contribuição de cada um desses brilhantes pensadores (Vigotski, Marx e Espinosa) à análise da relação entre subjetividade e desigualdade, no espaço do presente texto, é impossível. Mas vou destacar duas dimensões da subjetividade, justamente as mais esquecidas e discriminadas como perturbadoras da ordem social, do comportamento virtuoso e do conhecimento: os afetos e a imaginação. Inspirada em Vigotski e Espinosa, defenderei que a emoção e a criatividade são dimensões ético-políticas da ação transformadora, de superação da desigualdade, e que trabalhar com elas não é cair na estetização das questões sociais, ou solipcismo, mas sim um meio de atuar no que há de mais singular da ação política emancipadora.

Espinosa (1632-1677) contrapõe-se à concepção dominante em sua época, defendendo que as emoções não devem ser combatidas ou criticadas. E elas devem ser compreendidas não como um vício da natureza humana, mas como uma propriedade que lhe é tão pertinente como o calor e o frio (Espinosa, 1957).

A grande questão da filosofia espinosana é a servidão humana em todas as suas formas. O filósofo queria entender o que leva os homens a lutarem por sua escravidão como se fosse por sua liberdade, isto é, entender a servidão como ilusão de liberdade para encontrar os caminhos pelos quais a verdadeira liberdade pudesse se tornar desejada e alcançada. A resposta ele vai encontrar no sistema dos afetos, o que o levou a escrever um verdadeiro tratado das emoções em seu mais famoso livro, Ética (1957), no qual demonstra de forma geométrica que a vida ética começa no interior dos afetos, e não contra eles, pois constituem a base tanto da servidão como da liberdade.

Assim, nos ensina que as ações revolucionárias são inócuas se não se desbloqueiam as forças reprimidas da subjetividade em direção à alegria de viver, que, por sua vez, é a base da liberdade. Os homens se submetem à servidão porque são tristes, amedrontados e supersticiosos. Enredados na cadeia das paixões tristes, anulam suas potências de vida e ficam vulneráveis à tirania do outro, em quem depositam a esperança de suas felicidades. Por isso, afirma Espinosa, não se destrói uma tirania eliminando o tirano, pois outros o substituirão caso as relações servis não sejam destruídas. É preciso destruir as relações que sustentam a servidão (Espinosa, 1957).

Passo, agora, a destacar os pressupostos que levaram Espinosa a articular servidão e liberdade (ética) aos afetos.
O homem é um grau de potência, uma força interior para se conservar, perseverar na própria existência, um esforço de resistência, que Espinosa chama de conatus e, também, de apetite e de desejo (cupiditas) quando o apetite é consciente. $\mathrm{O}$ desejo é a própria essência do homem, é a força que nos leva ao encontro com algo que sentimos que compõe com a potência de nosso corpo e alma para se conservar (Espinosa, 1957, Parte III, Prop. IX, Esc.).

Essa força - é importante destacar - não se confunde com a luta pela sobrevivência darwiniana ou com o "sobrevivencialismo" " pós-moderno, um superinvestimento na sobrevida biológica com a abolição dos sentidos, sendo o indivíduo reduzido a simples corpo vivente, "mera aparência de vida que pensa apenas em evitar a morte", como descreve Deleuze (2002, p. 32). Perseverar na própria existência é mais que se conservar vivo, deixa claro Espinosa. É expansão do corpo e da mente na busca da liberdade, da felicidade, que são necessidades tão fundamentais à existência humana como o são os alimentos e os abrigos, e a reprodução biológica. Daí sua conclusão de que a luta pela emancipação é uma dimensão irreprimível do homem no seu processo de conservar-se, o que pressupõe passar da condição de escravo ao modo livre, da heteronomia à autonomia.

Essa ontologia espinosana é importante para superar a concepção de que a liberdade tem pouco valor para quem vive em estado de pobreza e que, portanto, não se justifica trabalhar a liberdade quando se passa fome. Ela nos lembra que, mesmo na miséria, os homens não estão reduzidos à sobrevida biológica, sem sutilezas psicológicas (Sawaia, 2007). Pesquisa com moradores de rua5 demonstra a veracidade desse postulado, ao constatar que eles sofrem por falta de dignidade e liberdade. O cerceamento de seu direito de escolher e de ser reconhecido gera tanto sofrimento quanto a falta de moradia, pois é fruto da falta de liberdade. "A liberdade é uma virtude, quer dizer, uma perfeição. Conseqüentemente, nada do que atesta impotência no homem se pode relacionar com a sua liberdade. ... Liberdade, com efeito, não suprime, mas, pelo contrário, coloca a necessidade da ação" (Espinosa, 1977, Cap. II, § 7 e 11, pp. 20-21).

Aqui cabe um esclarecimento: Espinosa fala em essência sem ser essencialista. Sua concepção de essência não é deiscência, uma tendência natural que se realiza por si e como causa de si6. A potência de conservação é também poder de ser afetado, o que significa que ela, apesar de ser irreprimível, varia de intensidade, a depender das intersubjetividades que me constituem, isto é, das afecções (affections) que meu corpo e minha mente sofrem nos bons ou maus encontros do passado, do presente e do futuro. 
Afeto (affectus) é justamente essa transição de intensidade, é transitio, passagem de um estado de potência a outro (Espinosa, 1957, parte III) gerada pelas afecções (affections) que meu corpo e minha mente recebem na existência. Portanto, ele tem duas dimensões: a da mudança, modificações que meu corpo e minha mente retêm na forma de emoções e sentimentos (affectus), e a da experiência da afetação (affection), isto é, a do poder de ser afetado. Aqui reside a principal contribuição de Espinosa à Psicologia, a relação positiva entre o poder que tem um corpo de ser afetado, na forma de emoções e sentimentos, e o seu poder de agir, de pensar e desejar. E como mente e corpo são uma mesma e única coisa, as afecções do corpo são afecções da alma, sem hierarquia ou relação causal entre eles. O que aumenta ou diminui a potência de meu corpo para agir aumenta ou diminui a potência de minha alma para pensar. Dessa flutuação depende a minha força vital de resistência, o que equivale à qualidade ética de minha existência.

Nessa concepção, os afetos não são estados psicológicos ou construtos linguísticos, mas condição e fundamento do ser e existir, portanto, da ética "cada um julga assim, ou avalia, segundo a sua afecção, qual é a coisa boa e qual é a má, qual a melhor, qual a pior" (Espinosa, 1957, Parte III, Prop. XXIX, Escólio). Aqui estão três contribuições importantes de Espinosa à Psicologia: (a) a junção indissociável entre corpo e mente e a relação entre o poder do corpo de ser afetado e sua potência de ação; (b) a junção indissociável entre ideia e emoção e (c) a junção indissociável entre afeto e ética.

Alegria é o sentimento que temos quando nossa capacidade de existir aumenta. Tristeza é definida por Espinosa como o resultado de uma afecção que diminui nossa capacidade de existir e nos tornamos passivos. "A paixão triste é um complexo que reúne o infinito do desejo e o tormento da alma, a cupidez e a superstição, para quem qualquer tipo de felicidade é uma ofensa" (Deleuze, 2002, p. 31).

Dentre as paixões tristes, ele destaca o medo e a esperança e demonstra a importância delas à manutenção das ditaduras. $\mathrm{O}$ medo ensandece o homem e perdura, quando alimentado por outras paixões como ódio, cólera, humilhação e aversão à felicidade (Espinosa, 1957, Parte IV, Prop. LXIII, Escólio). Ele é uma tristeza instável nascida da ideia de ocorrência de uma coisa futura de cujo desenlace duvidamos, com relação a que nada se pode fazer, senão esperar que não aconteça (Espinosa, 1957, Parte III, Definições XIII). Por isso, o medo equivale à impotência da alma que, dominada e submetida, imagina novos medos e nutre esperanças em ultrapassá-los. Não há esperança sem medo ou medo sem esperança. Ambos se nutrem no tempo e são as causas que originam e alimentam a superstição, a qual, segundo Espinosa, é a ignorância vestida de conhecimento, espalhando medo e loucura, e servindo de sustentação de tiranias (Chauí, 1987, p. 63).

Espinosa (1988, prefácio) denuncia três personagens que sustentam a servidão: o homem das paixões tristes, o homem que explora essas paixões, que precisa delas para manter o seu poder, e o homem que se entristece com elas - enfim, o escravo, o tirano e o sacerdote, respectivamente. $\mathrm{O}$ tirano precisa da tristeza das almas para triunfar, do mesmo modo que as almas tristes precisam do tirano para se prover e propagar. $\mathrm{O}$ que os une é o ódio e o ressentimento contra a vida.

Daí sua recomendação de que não se atinge a democracia pelo terror. O corpo político que nasce do medo e da impotência exprimirá essas condições em suas instituições (Chauí, 1987, p. 74). É preciso fortalecer as emoções alegres, que são correlatas ao conhecimento e à potência de existir/expandir "por necessidade da própria natureza" (Espinosa, 1957, Parte I, Definições VII):

Diz-se livre o que existe exclusivamente pela necessidade de sua natureza e por si só é determinado a agir; e dir-se-á necessário, ou mais propriamente, coagido, o que é determinado por outra coisa a existir e a operar de certa e determinada maneira ratione.

Mas não nos precipitemos em julgar Espinosa um otimista ingênuo. Dizer que a alma é ideia das afecções do corpo não significa que a alma tem sempre e imediatamente um conhecimento verdadeiro, que nossos desejos sempre nos levam a promover encontros que compõem com nossa potência e que as emoções alegres sempre potencializam a autonomia.

Nossa alma tem ideias imaginativas, isto é, baseadas nas imagens que nascem das afecções instantâneas, voláteis, dispersas (imediatas ou memoriosas) e, portanto, ilusórias, as quais constituem o primeiro nível de conhecimento - por exemplo, quando olhamos o sol, imaginando que ele está perto de nós; quando agimos por recompensa, sentindo-o como ato livre; e quando colocamos a própria felicidade na dependência das atenções recebidas da pessoa amada7. Quando ficamos presos a esse primeiro nível de conhecimento, das ideias imaginativas, estamos dominados por paixão, afeto característico de um modo de existir sustentado por relações (maus encontros) servis, características da desmesura de poder.

Aqui se tem outra importante contribuição de Espinosa à Psicologia, a distinção que estabelece entre afeto/paixão (passion) e afeto/emoção (motion). Paixão equivale às ideias ilusórias e à passividade (ser determinado a existir, desejar e pensar com base em imagens exteriores que operam como causas de nosso apetite). É a situação em que a força do conatus, tendo se tornado enfraquecida sob a ação de forças externas, submete-se 
a elas imaginando submetê-las e fica sujeita a forças contrárias que a puxam para lados opostos.

É ilusão (imagem) de força na fraqueza, que é definida literalmente por Espinosa como alienação. Alienado, o indivíduo não só não reconhece o poder externo que o domina, mas o deseja e se identifica com ele, perdendo a referência do seu conatus e, justamente por isso, provocando sua própria destruição ou a destruição do outro. A alienação torna cada um contrário a todos os outros, cada qual imaginando satisfazer seu desejo com a destruição do outro, percebido como obstáculo aos seus desejos, como no caso do ciúme e do suicídio, da superstição e do preconceito, ou da submissão ao desejo de quem se teme e/ou se admira.

Para salvar os homens da alienação, Espinosa esboça uma terapêutica das paixões no final da Parte $\mathrm{V}$ da Ética, cujo princípio orientador é o de que a paixão, embora seja da ordem da ilusão, não pode ser vencida pela razão, pelo simples fato de que razão e emoção não são funções distintas e independentes, ao contrário, operam juntas e em simultâneo. Portanto, razão sem afeto é abstração.

É importante lembrar que Espinosa é racionalista, mas não dualista (Deleuze, 2002). Para suprimir uma paixão, a razão precisa ser uma afecção. O conhecimento do bem e do mal puramente discursivo não prevalece sobre as paixões, pois é uma abstração que não nos une aos objetos. Apenas a fruição de um bem maior pode nos livrar da paixão. Isto significa que, em situação de servidão, somente quando os limites impostos à potência de vida pela paixão forem sentidos como afeto de tristeza, a expansão de meu corpo for sentida como alegria e a ignorância for experimentada como tristeza, daí nosso corpo e nossa alma passam a desejar conhecer as causas de nossos atos e de nossas necessidades, passando da paixão à ação. Ao compreender a natureza de nossas emoções, nós nos tornamos livres das ideias inadequadas (superstições) e sentimos alegria.

Temos exposta, aqui, a complexa ideia espinosana de razão como afeto supremo (Ferreira, 1997, p. 471), como desejo de verdade, uma alegria de pensar sem submissão a qualquer poder e a decisão de afastar tudo quanto cause medo e tristeza (Chauí, 1995, p.12).

Essas são algumas das reflexões do "filósofo da alegria e da liberdade" que o tornam tão atual e explicam sua eleição como fonte de inspiração dos mais importantes pensadores das Ciências Humanas: Hegel, Nietszche, Freud, Marx, Lacan, assim como do mais importante teórico da Psicologia sócio-histórica, referencial do presente texto, Vigotski.8

Vigotski (1918-1934) inspirou-se na filosofia monista de Espinosa e na teoria dialético-materialista de Marx para construir uma concepção de psiquismo como um sistema integrado de funções psicológicas, em que todas estão relacionadas entre si, ao corpo biológico, mediadas pela cultura e pelo contexto social, sem hierarquia e relação causal. Defende que é sobre essa união, sobre os nexos que a promovem e seu caráter mediático que a Psicologia deve se debruçar, pois é essa unidade que qualifica nossa condição humana: "Quando nos achamos em presença das individualidades humanas que revelam o grau máximo de perfeição ética e a mais maravilhosa vida espiritual, encontramo-nos diante de um sistema no qual o todo mantém relação com a unidade" (Vigotski, 1991b, p. 92).

Quando se rompem um ou mais nexos entre as funções psicológicas superiores (FPS), altera-se a correlação entre a vida intelectual e a afetiva, o que explica, segundo Vigotski (1997), as patologias psíquicas. Concorda com Espinosa de que as emoções têm um papel fundamental nesse sistema: "São esse organizador interno de nossos comportamentos, que retesam, excitam, estimulam ou inibem essas ou aquelas funções psicológicas" (Vigotski, 2001, p. 139). Define ainda que

Toda emoção é um chamamento à ação ou uma renúncia a ela. Nenhum sentimento pode permanecer indiferente e infrutífero no comportamento. Ao sermos afetados, se alteram as conexões iniciais entre mente e corpo, pois os componentes psíquicos e orgânicos da reação emocional se estendem a todas as funções psicológicas superiores iniciais em que se produziram, surgindo uma nova ordem e novas conexões. (Vigotski, 2001, p. 139)

Considera que o papel da emoção no sistema psicológico é tão importante a ponto de afirmar que "a separação do lado intelectual de nossa consciência de seu lado afetivo-volitivo constitui um dos defeitos básicos mais graves de toda psicologia tradicional" (Vigotski, 1993a, p. 24). São as emoções, em conjunto com o desejo e a necessidade, que constituem uma esfera do psiquismo bastante valorizada por Vigotski, a da motivação, que é a base afetivo-volitiva de nossa consciência e pensamento, e, portanto, contém o último porquê de nossas atividades e ideias: 9 "O pensamento não nasce de si mesmo, nem de outro pensamento, mas da esfera motivadora de nossa consciência, que abarca nossas inclinações e nossas necessidades, nossos interesses e impulsos, nossos afetos e emoções" (Vigotski, 1993a, p. 343). E é aí que as pesquisas devem buscar a explicação das ações e das falas individuais e coletivas.

Assim, Vigotski vai introduzindo a filosofia espinosana na ciência psicológica, com o objetivo de superar a visão negativa que, à época, esse campo do conhecimento tinha das emoções, consideradas como antagônicas à razão10. Nesse processo, ele não só traduz cientificamente as ideias de Espinosa como também as amplia de maneira brilhante. É na busca da compreensão da criatividade, da criação e da fruição do 
belo que reside a principal contribuição de Vigotski à filosofia espinosana: o papel da imaginação na liberdade humana, mediada pelas emoções, com base no vínculo da imaginação e do pensamento com a afetividade (Vigotski, 1993c).

Podemos resumir em duas de suas frases essa contribuição: "A espécie humana não vai parar de arrastar-se de quatro diante de Deus, czares e do capital apenas para curvar-se obedientemente diante das leis sombrias da hereditariedade e da seleção sexual cega" (2001, p. 463). Isso significa afirmar que liberdade é mais do que se libertar de tiranias, é livrar-se das leis da natureza. Diz ainda Vigotski: "As possibilidades de atuar com liberdade, que surgem na consciência do homem, estão estreitamente ligadas à imaginação" (1993c, p. 438), portanto, os homens só podem atingir um grau de liberdade se forem criativos.

Vigotski amplia a concepção espinosana de imaginação, passando-a de imagem aparente das afecções à base da criação. Toda emoção faz uso da imaginação, pois é ela que amplia a experiência11, permitindo ao sujeito se apropriar da experiência de outros, associar acontecimentos carentes de vínculos racionais, mudar o passado, antecipar o futuro e, assim, promover transformações (Sawaia, 2006) .

A imaginação, por sua vez, é produto de nossa capacidade de signalização, "capacidade humana de projetar algo mentalmente antes de transformá-lo em realidade", afirma Marx no Capital (s.d., p. 202), de projetar sentidos para além das leis da natureza, das leis sociais e das marcas do passado, permitindo, assim, presentificar o futuro em ações transformadoras. Daí a afirmação de que a capacidade de criar significados é a atividade revolucionária por excelência, que torna a criatividade possível e transforma a determinação social e biológica em mediação (Newman \& Holzman, 2002, p. 105).

Ao libertar a atividade e o pensamento da fisicidade e da materialidade social12, a capacidade de signalização permite a emergência da singularidade, uma vez que possibilita uma variação infinita dos sentidos de uma afecção provocada por um mesmo fenômeno, deixando claro, assim, que o mais importante no estudo das emoções não é a objetividade dos fatos, mas a dinâmica da vida humana. É só aí que os processos emocionais ganham sentido.

É por essa via analítica que Vigotski sustenta a ideia de sujeito que se constitui nas determinações sociais, mas como dimensão de resistência. Sujeito, para Vigotski, não é uma identidade cartesiana unificada ou uma espécie de centro da subjetividade, como também não é sujeito determinado. É potencialidade de desenvolvimento mediado pelas intersubjetividades e atividades. Partilha com Espinosa a ontologia de sujeito como liberdade e desenvolvimento, um homem para além da conservação e da reprodução, sempre aberto, com maior ou menor intensidade, às novas possibilidades, ao desenvolvimento e à fruição do belo, e ainda à criação. Ou seja, um agente ativo em seu próprio desenvolvimento, mas que não age em terreno de sua própria escolha. Faz-se a si mesmo de acordo com o contexto social, que define as alternativas referentes à sua realização.

Essa ontologia se traduz na teoria vigotskiana do desenvolvimento, cuja base é uma fé inabalável no desenvolvimento humano em direção à sua maior complexidade. Também se traduz na sua concepção de atividade revolucionária, baseada no conceito de Zona de Desenvolvimento Proximal (ZDP) (Vigotski, 2001), uma qualidade de relação e de aprendizagem que potencializa nas pessoas as funções emergentes, para aquilo que é ainda potência individual de desenvolvimento, colocando à disposição dos sujeitos habilidades, conhecimentos e experiências que lhes permitam estimular os nexos entre imaginação, emoção, pensamento e vontade.

A arte tem papel importante nessa práxis. Para Vigotski, a Psicologia não se limita ao psicológico, mas abrange a totalidade de como as pessoas vivem suas vidas, o que indica que seu desenvolvimento criativo, emocional e artístico precisa ser estimulado, quando se deseja criar um novo homem (Newman \& Holzman, 2002, p. 179).

Não é por acaso que o seu primeiro livro é Psicologia da arte, em que ele cunha duas expressões instigantes para se referir à união entre imaginação, emoção e criatividade: arte como "técnica das emoções" e "emoções inteligentes", numa clara alusão à distinção espinosana entre afeto/ação (emoção) e afeto/passividade (paixão). Seguindo essa linha analítica, Vigotski elege a catarse para explicar a recepção da obra de arte, atribuindo-lhe um sentido próximo à concepção espinosana de terapêutica das paixões. Catarse não é apenas a descarga de sentimentos com a sua consequente tranquilização. Ela se caracteriza pelo confronto de paixões contrárias, que gera a complexa transformação dos sentimentos. A arte suscita em nós emoções voltadas a sentidos opostos ao habitual e, ao pôr em choque impulsos contrários, destrói paixões, acarretando a complexa transformação dos sentimentos (Vigotski, 1998, p. 270).

E a desigualdade social? Qual a contribuição que a filosofia da alegria de Espinosa e a teoria sócio-histórica libertária de Vigotski trazem à sua compreensão e à práxis psicossocial transformadora?

A desigualdade social se caracteriza por ameaça permanente à existência. Ela cerceia a experiência, a mobilidade, a vontade e impõe diferentes formas de humilhação. Essa depauperação permanente produz 
intenso sofrimento, uma tristeza que se cristaliza em um estado de paixão crônico na vida cotidiana, que se reproduz no corpo memorioso de geração a geração. Bloqueia o poder do corpo de afetar e ser afetado, rompendo os nexos entre mente e corpo, entre as funções psicológicas superiores e a sociedade. Deleuze (2002, p. 106) retrata bem esse processo ao explicar a concepção espinosana de tristeza: "na tristeza, nossa potência (conatus) serve toda ela para investir a marca dolorosa e para destruir o objeto que a causou. Assim, imobilizada, nossa potência só pode reagir e não agir", torna-se potência de padecimento, reduzindo nosso esforço de perseverar na própria existência ao sobrevivencialismo negador da vida.

A relação entre as ameaças provenientes da desigualdade social e as respostas afetivas dos que a elas se assujeitam compõe um processo psicológicopolítico poderoso à reprodução da desigualdade, que meu núcleo de pesquisa (NEXIN) conceitua de sofrimento ético-político. Assim fazemos para distingui-lo do sofrimento ontológico a que todos os seres vivos estão sujeitos, ao qual se soma. Trata-se de sofrimento/paixão, gerado nos maus encontros caracterizados por servidão, heteronomia e injustiça, sofrimento que se cristaliza na forma de potência de padecimento, isto é, de reação e não de ação, na medida em que as condições sociais se mantêm, transformando-se em um estado permanente da existência. É o sofrimento, por exemplo, do homem em situação de pobreza que, amedrontado, fraco e muitas vezes deslumbrado com a vida de luxo, vive a ilusão de liberdade e espera recompensas, ou mesmo remete a possibilidade de felicidade e liberdade sempre ao futuro (paradigma da redenção).

A filosofia de Espinosa, elaborada para orientar os homens a se livrarem da servidão por meio da emoção, e a psicologia sócio-histórica de Vigotski, voltada à potencialização da liberdade e do desenvolvimento humano "a níveis cada vez mais elevados", ajudam a entender e orientar formas de superação desse sofrimento/paixão. No prefácio do caderno V da Ética, Espinosa fala em determinar os "remédios às paixões", visando à potência da liberdade humana. Vou denominar esse conjunto de reflexões de "terapêutica das paixões"13 , e, por associação, usar a expressão "terapêutica estético-política" para me referir à práxis vigotskiana de liberdade.

Ambas nos lembram que:

- Viver é mais que sobreviver. O homem tem necessidade, sim, de pão, mas igualmente de bons encontros potencializadores de liberdade, felicidade, criação e fruição do belo.

- A transformação social não se dá pela derrubada do tirano. Ela requer ações diferentes, mas combinadas para combater as relações de servidão, e uma delas é sempre a mais urgente: agir no sofrimento ético-político.
Ambas promovem um giro ontológico que altera fundamentalmente duas ideias dominantes que legitimam a criação de um sujeito político desprovido de sensibilidade e vontade na sociedade contemporânea, que são: a busca da felicidade é um ato de egoísmo, portanto é antagônica à ação política, e que é preciso ser consciente para ser livre. Espinosa e Vigotski defendem justamente o contrário, que a busca da felicidade é um ato político e que só se é consciente quando se é livre, isto é, quando a consciência resultar de uma decisão interior, autônoma, e não de obediência a um comando ou pressão externa14. "Liberdade de pensamento e de expressão e a busca da felicidade não são perigosas para a paz e segurança do Estado. Ao contrário, são suas condições" (Chauí, 2003, p. 61).15

Ambas as terapêuticas apontam procedimentos inusitados à atividade revolucionária, como estimular a criatividade vigotskiana e a felicidade espinosana, demonstrando que elas são fundamentais à passagem do momento passional-ilusório e reprodutor ao momento afetivo-transformador.

Somente quando os limites impostos ao corpo forem sentidos como afetos tristes e sua expansão for sentida como alegria, somente quando a ignorância for experimentada como tristeza e pensar livre como alegria, das paixões passa-se à ação. A alegria e a criatividade potencializam a força do nosso corpo e da nossa mente para não capitularmos ante as tragédias que a desigualdade social nos reserva, bem como para mantermos aceso nosso desejo de nos organizarmos em mil diferentes níveis coletivos para resistir ao mal. Potencializam, ainda, nossa sensibilidade de nos alegrarmos com nossa descomoditização e nos indignarmos com a desigualdade social.

E o que é muito importante: as ontologias espinosana e vigotskiana nos unem inexoravelmente aos outros e ao social. A consciência/sentimento de que nossa potência de passar da passividade à atividade só é possível por meio do outro nos torna comprometidos socialmente, não por obrigação, mas como ontologia. E são os afetos os responsáveis pela união dos esforços (conatus), em nos fazermos um, como se fôssemos uma única mente e um único corpo. Essa união de corpos e mentes constitui um sujeito político coletivo, a "multitudo" (Espinosa, 1977, IV, VII e VIII)16, categoria política fundamental, pois, como afirma Espinosa, o desejo de resistência nasce do sentimento de indignação17. Mas resistir não é só se indignar. O direito de derrubar a tirania depende da força para fazê-lo. Essa força, em situação de desmesura do poder, depende de uma potência de agir coletiva conquistada pela união de conatus, a qual, por sua vez, é favorecida quando a lógica dos afetos permite a percepção da amizade e da generosidade como algo útil (Chauí, 2003, p. 250). 
Em suma, essas são algumas implicações da contribuição à práxis psicossocial da Psicologia de dois pensadores que não se deixaram cercear pelos paradigmas dos conhecimentos dominantes à sua época histórica e procuraram denunciar tudo o que nos leva a depreciar a vida.

As terapêuticas das paixões e da criação, se não acionam a revolução em curto prazo, com certeza asseguram que a transformação ocorra de forma que o novo sistema que irá emergir seja melhor e nunca pior, pois ataca a causa da servidão na menor unidade da vida social: o desejo de cada um e de todos.

\section{Notas}

1 Na década de 1970, os congressos da SIP se tornaram fóruns privilegiados de debates sobre a crise da Psicologia, especialmente da latino-americana.

2 As obras mais citadas de Marx por Vigotski são $A$ ideologia alemã (2007), Manuscritos econômicos e filosóficos (1987) e O capital (s.d.). No texto O significado histórico da crise da Psicologia (1927, ver edição de 1991a), ele informa que seu objetivo é escrever "O capital da Psicologia", para demonstrar a unidade indissociável do funcionamento do psiquismo e a sua mediação social.

3 As obras mais citadas de Espinosa por Vigotski são o Livro III da Ética (1957) e o Tratado da correção do intelecto (1997).

4 Agamben (2007) também usa a expressão vida nua e homo sacer para se referir ao sobrevivencialismo. Ver Pelbart (2008).

5 Sawaia, B. B. "Subjective indicators of exclusion: health, disqualification and breakdown of social ties". Pesquisa realizada como parte de um Projeto CAPES/COFECUB sobre Trabalho, Saúde e Laços Sociais- NEXIN/NEPUR/PUCSP, 2003

6 Essa força de expandir a vida é potência e não deiscência, o que significa que ela não é uma tendência que vai inexoravelmente ocorrer. A potência de vida é aumentada ou diminuída nos encontros com outros corpos e mentes, sofrendo a ação de ideias, superstições e ações do outro, no sentido ou de maior autonomia ou de heteronomia. Distingue também estado de essência. Estado são as propriedades não essenciais, que é maior que a essência. Daí sua afirmação de que a essência é livre, mas a existência é determinada. Eu tenho a propriedade de ser, mas o quanto eu o serei é estado (livro III da Ética). Para maior demonstração de que Espinosa não é essencialista, ver Garret (1997, Cap. 5).

7 Sobre o exemplo do sol, ver Ética II, prop. XXXV, esc.; sobre felicidade, ver Ética IV; e sobre recompensa, ver Tratado teológico-político (1977, p. 144 ), no qual Espinosa distingue o cidadão e o escravo pelos motivos que os levam a obedecer. O sábio não age por recompensa, mas pelo exercício livre da própria intelectualidade.

8 Sobre a influência de Espinosa em Hegel, Nietszche, Marx e Freud, ver Yovel (s.d.). Ver também Chauí, M. (1983).

9 Após ter procurado aplicar à Psicologia o conceito de ativi- dade prática (anos 20), nos anos 30 passa a considerar como sua tarefa central a análise das motivações, entendendo que é por meio delas que a atividade determina os processos psíquicos e vice-versa.

10 "Espinosa mostrou essas ideias no plano filosófico ... Resta para a psicologia a tarefa de apresentá-las como verdade científica" - afirma Vigotski no texto Sobre os sistemas psicológicos (1991b, p. 92).

11 Vigotski, no livro Psicologia da arte (1998, p. 258), fala da lei do signo emocional comum e da lei da dupla expressão emocional para explicar a influência do fator emocional nas combinações da imaginação. Tudo o que nos causa emoção coincidente tende a se unir, mesmo que não se veja semelhança alguma entre elas. Daí sua afirmação de que a lógica interna dos sentimentos é o aspecto mais subjetivo da imaginação e que todas as noções geradas pela imaginação são verdadeiras, apesar da afecção não corresponder a nenhum conteúdo real.

12 Segundo Lukács (1979, p. 19), o significado é uma objetividade que não tem analogia na natureza. Como exemplo, cita uma afirmação irônica da Marx aos economistas de que "até agora, nenhum químico conseguiu descobrir valor-de-troca em pérolas ou diamantes" (Marx, s.d., p. 92).

13 Sobre a presença de uma psicoterapia na obra de Espinosa, ver Bennett, J. (1984).

14 Mais reflexões sobre a concepção de Espinosa de consciência como produto de liberdade e de autonomia, ver Chauí (1998).

15 Ideia defendida também por Amartya Sen (2001), que demonstra, por meio de números, que a liberdade é condição de desenvolvimento econômico.

16 Sobre as ideias espinosanas de multitudo e de vontade comum, relacionada ao Direito Civil, ver Chaú (2003), especialmente da página 234 a 314 .

17 Indignação é o ódio a alguém que faz mal a outrem, define Espinosa no livro III da Ética, Definição das Paixões, XX. Para melhor compreensão da dimensão política desse sentimento, ver Chauí (2003, p. 272).

\section{Referências bibliográficas}

Agamben, G. (2007). Homo Sacer: o poder soberano e a vida nua I. Belo Horizonte: Ed. UFMG.

Bennett, J. (1984). Un Estúdio de La Ética de Spinoza. México: Fondo de Cultura Económica.

Bodei, R. (1995). Geometría de las pasiones. México: Fondo de Cultura Económica.

Chauí, M. (1983). Marx e a democracia (o jovem Marx leitor de Espinosa). In L. Konder (Org.), Por que Marx? (pp. 257-291) Rio de Janeiro: Ed Graal.

Chauí, M. (1987). Sobre o medo. In A. Novaes (Org.), Os sentidos da paixão (pp. 35-75). São Paulo: Companhia das Letras.

Chauí, M. (1995). Espinosa: uma filosofia da liberdade. São Paulo: Moderna.

Chauí, M. (1998). Ética e violência. Teoria e Debate, 39, 32-41.

Chauí, M. (2003). Política em Espinosa. São Paulo: Cia. das Letras.

Deleuze, G. (2002). Espinosa: filosofia prática. São Paulo: Escuta.

Durkheim, E. (2003). O suicídio (Alex Marins, Trad.). São Paulo: Martin Claret. 
Espinosa, B. (1957). Ética (Lívio Xavier, Trad., $3^{\text {a }}$ ed.). São Paulo: Atenas.

Espinosa, B. (1977). Tratado politico (2 $2^{\mathrm{a}}$ ed.). Lisboa: Editorial Estampa.

Espinosa, B. (1988). Tratado teológico-político. Lisboa: Imprensa Nacional/ Casa da Moeda.

Espinosa, B. (1997). Tratado da correção do intelecto. In Pensamentos metafísicos. Tratado da correção do intelecto. Tratado político. Correspondência (C. L. de Mattos et al., Trads., Coleção Os Pensadores, pp. 103-139). São Paulo: Nova Cultural.

Ferreira, M. L. R (1997). A dinâmica da razão na filosofia de Espinosa. Lisboa: Fund. Calouste Gulbenkian/Junta Nac. de Inv. Cient. e Tec..

Freud, S. (1968). Obras Completas. Madrid: Editorial Biblioteca Nueva.

Garret, D. (1997). The Cambridge Companion to Espinosa. New York: Cambridge University Press.

Lukács, G. (1979). Ontologia do ser social: os principios ontológicos fundamentais de Marx. São Paulo: Livraria Ed. Ciências Humanas.

Marx, K. (1987). Manuscritos econômicos e filosóficos (4ª ed., J. C. Bruni, Trad.). São Paulo. Nova Cultural.

Marx, K. (s.d.). O capital I ( $4^{\mathrm{a}}$ ed.). Rio de Janeiro: Civilização Brasileira. (Original publicado em 1890)

Marx, K. \& Engels, F. (2007). A ideologia alemã (1 $1^{\mathrm{a}}$ ed., M. Backes, Trad.). Rio de Janeiro: Civilização Brasileira.

Newman, F. \& Holzman, L. (2002). Lev Vygotsky: cientista revolucionário. São Paulo: Loyola.

Pelbart, P. (2008). Vida e morte em contexto de dominação biopolítica. Acesso em 25 de agosto, 2009, em http://www.iea. usp.br/iea/textos/pelbartdominacaobiopolitica.pdf

Sawaia, B. B. (2001). Sílvia Lane (Coleção Pioneiros da Psicologia Social). São Paulo: CFP/Imago.

Sawaia, B. B. (2006). Introduzindo a afetividade na reflexão sobre estética, imaginação e constituição do sujeito. In S. Z. Da Ros, K. Maheirie, \& A. V. Zanella, A.V. (Orgs.), Relações estéticas, atividade criadora e imaginação: sujeitos e (em) experiência (pp. 85-95). Florianópolis: NUP/UFSC.

Sawaia, B. B. (2007). O sofrimento ético-político como categoria de análise da dialética exclusão/inclusão. In B. B. Sawaia (Org.), As artimanhas da exclusão: uma análise ético-psicossocial da desigualdade (7 ${ }^{\mathrm{a}}$ ed., pp. 97-119). Petrópolis, RJ: Vozes.

Sen, A. (2001). Desenvolvimento como liberdade. São Paulo: Cia. das Letras.

Vigotski, L. S. (1987). Imaginación y el arte en la infancia. Cidade do México: Hispánicas.
Vigotski, L. S. (1991a). El significado histórico de la crisis de la psicología: una investigación metodológica. In Obras escogidas (Vol. 1, pp. 257-407). Madrid: Visor.

Vigotski, L. S. (1991b). Sobre los sistemas psicológicos. In Obras escogidas (Vol. 1, pp.71-95). Madrid: Visor.

Vigotski, L. S. (1991c). El problema de la consciencia. In Obras escogidas (Vol. 1, pp. 119-133). Madrid: Visor.

Vigotski, L. S. (1993a). Pensamiento e lenguaje. In Obras escogidas (Vol. 2, pp. 9-349). Madrid: Visor.

Vigotski, L. S. (1993b). El problema y el método de investigación. In Obras escogidas (Vol. 2, pp.15-29). Madrid: Visor.

Vigotski, L. S. (1993c). La imaginación y su desarrollo en la edad infantil. In Obras escogidas (Vol. 2, pp.423-439). Madrid: Visor.

Vigotski, L. S. (1997). El problema del retraso mental. In Obras escogidas (Vol. 5, pp. 249-275). Madrid: Visor.

Vigotski, L. S. (1998). Psicologia da arte (P. Bezerra, Trad.). São Paulo: Martins Fontes.

Vigotski, L. S. (2001). Psicologia pedagógica. São Paulo: Martins Fontes.

Yovel, Y. (s.d.). Espinosa e outros hereges. Lisboa: Imprensa Nacional/ Casa da Moeda.

Bader Burihan Sawaia possui graduação em Ciências Sociais, mestrado e doutorado em Psicologia Social pela PUC-SP. Atualmente é professora titular da Pontifícia Universidade Católica de São Paulo e colaboradora da Universidade de São Paulo - Instituto de Estudos Avançados - IEA/USP. É parecerista ad hoc do Conselho Nacional de Desenvolvimento Científico e Tecnológico e da Fundação de Amparo à Pesquisa do Estado de São Paulo. Endereço para correspondência: PUC de São Paulo - Programa de Pós-Graduação em Psicologia Social. Rua Monte Alegre, 984, Perdizes. CEP: 05015-000. São Paulo, SP.

Email: badbusaw@pucsp.br

Psicologia e desigualdade social: uma reflexão sobre liberdade e transformação social

Bader Burihan Sawaia

Recebido em: 21/05/2009

Revisado em: 31/08/2009

Aceite final em: 05/01/2010 